\title{
Analysis of the Cesarean Index in Patients Primigests of Different Age Groups
}

\author{
Mayela Diamantina Cruz Gutiérrez* and Abel Guzman-Lopez \\ Department of Obstetrics and Gynecology, School of Medicine and University Hospital “Dr. Jose Eleuterio Gonzalez”, Universidad \\ Autonoma de Nuevo Leon (U.A.N.L.), México
}

*Corresponding author: Mayela Diamantina Cruz Gutiérrez, Department of Obstetrics and Gynecology, University Hospital "Dr. Jose Eleuterio Gonzalez", Universidad Autonoma de Nuevo Leon (UANL), Av. Francisco I. Madero s/n, Col. Mitras Centro, CP. 66460, Monterrey, Nuevo Leon, Mexico

\section{ARTICLE INFO}

Received: 㓞 April 29, 2020

Published: 慧 May 22, 2020

Citation: Mayela Diamantina Cruz G, Abel Guzman-Lopez. Analysis of the Cesarean Index in Patients Primigests of Different Age Groups. Biomed J Sci \& Tech Res 27(5)2020. BJSTR. MS.ID.004567.

Keywords: Cesarean section; Cephalopelvic Disproportion Due to Pelvic Tightness; Dystocia Induction; Fetal Suffering.

\section{Abstract}

Introduction: Cesarean section as a birth route is associated with an increased risk of long-term complications, such as placenta previa, placental accretion, and postoperative, such as endometritis, dehiscence, and / or surgical wound infection.

Objective: To describe the main indications in primigraphic patients divided into 3 age groups who attended the "Dr. José Eleuterio González" for your attention from January 1, 2016 to December 31, 2016.

Materials and methods: Cross-sectional, observational, descriptive and prospective study in 384 patients. The pre-operative sheet of the clinical record was analyzed: the indication of the surgical procedure and information was collected from the newborns (weight, height, Apgar and Capurro), as well as aggregate pathologies.

Results: Group 1 was made up of 281 patients with an average age of 16.8 years, group 2 included 101 patients with a mean age of 21.5 years, and group 3 consisted of 2 patients. The main indications for cesarean section were DCPxPN (33.9\%), contraction dystocia (14.6\%) and failed induction (13\%). Of the total number of patients admitted, $10.6 \%$ were admitted with HDPC of which, $31.7 \%$ classified as gestational hypertension, $36.58 \%$ were categorized as mild preeclampsia, $21.95 \%$ ended as severe preeclampsia, and $9.75 \%$ were categorized as eclampsia.

Conclusion: There is no difference between the main indications for caesarean section among the studied population (women younger than 20 years old, aged between 21 - 35 years old and older than 36 years old).

\section{Introduction}

In the mid-1980s, the World Health Organization (WHO) proposed a $15 \%$ standard for cesarean births. There are many reasons that have been put forward to explain this excess of caesarean sections: the perception that providers have that it is a safer procedure than vaginal delivery; the decrease in the obstetric abilities of the personnel in charge of the delivery care; the increasing age of mothers; the increased technological capacity to detect fetal distress; the preference for this procedure manifested by certain sectors of society, and various economic incentives related to private insurance [1]. The increase in caesarean sections that have no clinical justification worries health authorities and health service providers because it raises the costs of medical care, and exposes the mother and the product to unnecessary risks [1]. Taking into account the information from ENSANUT 2012 on the birth order of deliveries that occurred from 2007 to 2012, a greater trend of performing a cesarean section is observed when the birth is the first or the second (50.5 and $51.2 \%$, respectively) propensity which decreases from the third (43.9\%) to the sixth and more births $(22.7 \%)$. This behavior is accentuated in women 20 years of age and older, so that those 35 years of age and older have extremely high percentages of performing this surgical procedure, especially when the order of birth is the first or second (90.7 and $72.5 \%$, respectively) [2]. 
Adolescents are considered to be a group considered to be in good health; it is exposed to various events such as accidents, suicides, pregnancy and related complications. In addition to them, there are sexually transmitted infections, tobacco and / or drug use [3]. Adolescence can be divided into 3 stages: A) Early adolescence between 12 and 13 years of age, B) Middle adolescence between 14 and 16 years of age and C) Late adolescence between 17 and 21 years of age. It is in the middle adolescence in which most of the physiological growth of young people is completed; they reach their height and weight as adults and have the physical capacity to have babies [4]. According to the WHO, approximately 16 million young people between the ages of 15 and 19 and about 1 million under the age of 15 have one baby each year, mainly in low-income countries [5]. It is estimated that 70,000 adolescent women die each year due to pregnancy before they have the physical maturity necessary for motherhood. It is because of this that adolescent pregnancy and birth are considered risky [5]. The relation of teenage pregnancy with adverse events has been demonstrated in the product; such as preterm delivery, low birth weight, small product for gestational age, preeclampsia, NICU admissions, neonatal death, intrauterine death, neonatal asphyxia, respiratory distress syndrome (RDS), or trauma at birth $[6,7]$.

All together with the risks that arise in patients such as anemia, hypertensive disease of pregnancy to classify (HDPC), urinary tract infection, abortion, sexually transmitted infections (STIs), fever or puerperal sepsis, as well as an increase in the rates of caesarean section due to the cephalopelvic disproportion $[8,6]$. Teenage pregnancies are more likely in vulnerable populations such as poor, rural, and poorly industrialized communities [5]. The hypothesis raised was that the indications for caesarean section in the 3 groups of primigraphic patients to be analyzed are different from each other. As well as the objective of this study is to analyze the main indications for caesarean section and obstetric complications in primiparous patients younger than 20 years, from 21 to 35 years old and over 36 years old.

\section{Materials and Methods}

An observational, descriptive and prospective study was carried out at the University Hospital "Dr. Jose Eleuterio Gonzalez" from UANL, registered in the Hospital Ethics Committee with registration number GI16-00005. The number of patients required for this study was 384 patients, including prime-term patients with full-term pregnancy ( $>37$ weeks gestation) without underlying or chronic pathologies. Patients with multiple pregnancies were excluded. The calculation of the sample was carried out (Figure 1) where $p$ is the proportion of subjects carrying the study, which in this case versus belongs to $50 \%$ of the population. $q$ is the complement of the subjects that does not have the study variable precision or degree of magnitude of which we are willing to accept (5\%) and Z $\alpha$ which is the distance from the mean of the proposed significance value that for 0.05 would have to be 1.96 (Figure 2). The variables that were analyzed in the patient were: Age (years), weight (gr), height (cm), complications of caesarean section (dehiscence or wound infection, formation of seroma or hematoma, uterine atony, etc.) and the Cause of indication for caesarean section. The variables that were analyzed for the product were: Apgar: It is a method which provides a global vision of the state of the newborn at the time of birth.

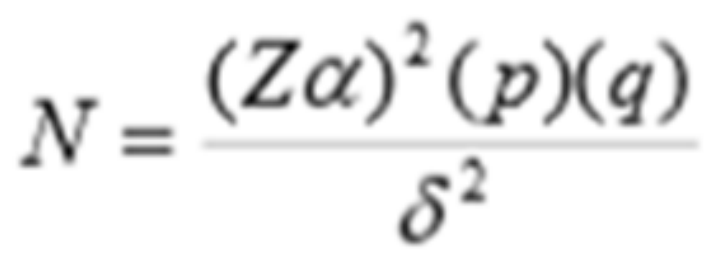

Figure 1: Calculo del tamaño de la muestra.

$$
\begin{aligned}
& N=\frac{(1.96)^{2}(0.5)(0}{(0.05)^{2}} \\
& N=\frac{(1.96)^{2}(0.25)}{(0.05)^{2}} \\
& N=\frac{0.9604}{0.0025}
\end{aligned}
$$$$
N=384.16
$$

Figure 2: Calculo del tamaño de la muestra final.

The rating varies from 0 to 10 and the parameters it evaluates are: heart rate, respiratory rate, muscle tone, reflex of irritability, color, the weight was also included according to gestational age, capurro: which is used for neuromuscular and physical evaluation. This classification takes 4 physical parameters (skin texture, size of the mammary gland, plantar folds and shape of the ear) and two neurological parameters (head drop and scarf maneuver). A sum is obtained to which 200 is added and is divided by 7 and presents a margin of error of 1 week or so [9], and admission to the NICU was also taken into account. The ICD-10 (International Classification of Diseases, Version 10) of the single delivery by cesarean section was obtained and the records of all the primigraphic patients were requested from the Department of Gynecology and Obstetrics, which 
were divided into the 3 groups according to age (see forward), who received care at the end of the pregnancy at the University Hospital “Dr. José Eleuterio González" within the period from January 1, 2016 to December 31, 2016. The pre-operative sheet was analyzed and the indication of the procedure was captured in an Excel sheet. At the same time the product file was requested and the diagnoses of the Newborn Sheet (Apgar, Capurro, Weight) were captured, as well as if the patient had any pathology that required more attention.

\section{Statistic Analysis}

The results were reported in contingency tables, frequencies, percentages, measures of central tendency and dispersion. Qualitative variables were analyzed with the chi square statistic. A value of $p<.05$ will be considered statistically significant. Statistical analysis will be performed with IBM SPSS version 20 (SPSS, Inc., Armon, NY).

\section{Results}

The main indications for caesarean section were analyzed in 384 primigraphic patients who attended the University Hospital Dr. José Eleuterio González of the UANL; This sample was divided into 3 groups, based on age: Patients younger than 20 years old, patients between 21 - 34 years old, patients older than 36 years old.

Tabla 1: Promedio de edad materna por grupo de edad.

\begin{tabular}{|c|c|}
\hline Age group & Ranges (years) \\
\hline Under 20 years old & $18(17-19)$ \\
\hline $21-35$ years & $23(21-26)$ \\
\hline Over 36 years & $37.5(37-37.5)$ \\
\hline
\end{tabular}

Tabla 2: Indication of Cesarean Section in the General Population.

\begin{tabular}{|c|c|c|}
\hline Diagnosis & Frequency & Percentage (\%) \\
\hline CPDxPN & 130 & 33.9 \\
\hline Contraction dystocia & 56 & 14.6 \\
\hline Failed induction & 50 & 13.0 \\
\hline Acute fetal distress & 34 & 8.9 \\
\hline Condylomatosis & 32 & 8.3 \\
\hline Pelvic presentation & 29 & 7.6 \\
\hline Macrosomic product & 28 & 7.3 \\
\hline CTGR class II & 12 & 0.1 \\
\hline OPP & 3 & 0.5 \\
\hline Eclampsia & 2 & 0.5 \\
\hline Preeclamsia severasia & 2 & 0.5 \\
\hline Uncertain fetal status & 2 & 0.3 \\
\hline Product in transverse & 1 & 0.3 \\
\hline situation & 1 & 0.3 \\
\hline Umbilical cord prolapse & 384 & 100.0 \\
\hline OTT (+) & 1 & \\
\hline Placental insufficiency & 1 & 0.3 \\
\hline
\end{tabular}

Note: ${ }^{*}$ CPDxPN: Cephalo-Pelvic Disproportion Due to Pelvic Narrowness
Tabla 3: Indications for caesarean section in group 1 - under 20 years of age.

\begin{tabular}{|c|c|c|}
\hline Diagnosis & Frequency & Percentage (\%) \\
\hline CPDxPN & 97 & 34.5 \\
\hline Contraction dystocia & 43 & 15.3 \\
\hline Failed induction & 36 & 12.8 \\
\hline Acute fetal distress & 25 & 8.9 \\
\hline Condylomatosis & 23 & 8.2 \\
\hline Macrosomic product & 19 & 6.8 \\
\hline Pelvic presentation & 18 & 6.4 \\
\hline CTGR class II & 9 & 3.2 \\
\hline OPP & 2 & 0.7 \\
\hline Eclampsia & 2 & 0.7 \\
\hline Preeclamsia severasia & 2 & 0.7 \\
\hline Product in transverse & 1 & 0.4 \\
\hline situation & 1 & 0.4 \\
\hline Uncertain fetal status & 1 & 0.4 \\
\hline Umbilical cord prolapse & 1 & 0.4 \\
\hline OTT (+) & 1 & 0.4 \\
\hline Placental insufficiency & 281 & 100.0 \\
\hline Total & & 0.4 \\
\hline
\end{tabular}

Note: *CPDxPN: Cephalo-Pelvic Disproportion Due to Pelvic Narrowness

Tabla 4: Indications for caesarean section in group 2 - patients between 21 - 35 years.

\begin{tabular}{|c|c|c|}
\hline Diagnosis & Frequency & Percentage (\%) \\
\hline CPDxPN & 33 & 32.7 \\
\hline Failed induction & 14 & 13.9 \\
\hline Contraction dystocia & 13 & 12.9 \\
\hline Pelvic presentation & 11 & 10.9 \\
\hline Condylomatosis & 9 & 8.9 \\
\hline Acute fetal distress & 9 & 8.9 \\
\hline Macrosomic product & 8 & 7.9 \\
\hline CTGR class II & 3 & 3.0 \\
\hline Uncertain fetal status & 1 & 1.0 \\
\hline Total & 101 & 100.0 \\
\hline
\end{tabular}

Note: ${ }^{*} \mathrm{CPDxPN}$ : Cephalo-Pelvic Disproportion Due to Pelvic Narrowness

Tabla 5: Indications for caesarean section in group 3 - over 36 years.

\begin{tabular}{|c|c|c|}
\hline Diagnosis & Frequency & Percentage (\%) \\
\hline Macrosomic product & 1 & 50.0 \\
\hline OPP & 1 & 50.0 \\
\hline Total & 2 & 100.00 \\
\hline
\end{tabular}

Of the total population (384), 281 comprised the group of patients under the age of 20 , which is equivalent to $73.17 \%$; 101 patients made up the second study group, which is equivalent to $26.30 \%$; the last group corresponding to the population older 
than 35 years was integrated by 2 patients, corresponding to $0.52 \%$ (Table 1). According to the analysis, the main indications for cesarean section are summarized in (Table 2). Indications for caesarean section according to age group were described (Tables 3-5). A comparison was made of the frequency, in percentage (\%), of the indications for caesarean section in the 3 age groups (Table 6). Analyzing the weights of the patients, their BMI was classified according to the result that overweight and obesity grade 1 prevail in our population (Table 7). With regard to cases of hypertensive disease during pregnancy, the results are reflected in (Table 8), which establishes the percentage of patients who have hypertensive figures at the time of admission, and is in (Table 9) in which a description is made of the different prevalent HDPCs in the population.

Tabla 6: Comparative analysis of indications between the group under 20 years of age and over 21 years ofage.

\begin{tabular}{|c|c|c|c|}
\hline Diagnosis & Under 20 years old & Over 21 years old & Total \\
\hline CPDxPN & $97(45.5 \%)$ & $33(32 \%)$ & $130(33.9 \%)$ \\
\hline Contraction dystocia & $43(15.3 \%)$ & $13(12.6 \%)$ & $56(14.6 \%)$ \\
\hline Failed induction & $36(12.8 \%)$ & $14(13.6 \%)$ & $34(13 \%)$ \\
\hline Acute fetal distress & $25(8.9 \%)$ & $9(8.7 \%)$ & $32(8.3 \%)$ \\
\hline Condylomatosis & $23(8.2 \%)$ & $9(8.7 \%)$ & $29(7.6 \%)$ \\
\hline Pelvic presentation & $18(6.4 \%)$ & $11(10.7 \%)$ & $28(7.3 \%)$ \\
\hline Macrosomic product & $19(6.9 \%)$ & $9(8.7 \%)$ & $12(3.1 \%)$ \\
\hline CTGR class II & $9(3.2 \%)$ & $3(2.9 \%)$ & $3(0.8 \%)$ \\
\hline OPP & $2(0.7 \%)$ & $1(1 \%)$ & $2(0.5 \%)$ \\
\hline Eclampsia & $2(0.7 \%)$ & $0(0 \%)$ & $2(0.5 \%)$ \\
\hline Preeclamsia severasia & $2(0.7 \%)$ & $0(0 \%)$ & $2(0.5 \%)$ \\
\hline Uncertain fetal status & $1(0.4 \%)$ & $1(1 \%)$ & $1(0.3 \%)$ \\
\hline Product in transverse situation & $1(0.4 \%)$ & $0(0 \%)$ & $1(0.3 \%)$ \\
\hline Umbilical cord prolapse & $1(0.4 \%)$ & $0(0 \%)$ & $1(0.3 \%)$ \\
\hline OTT (+) & $1(0.4 \%)$ & $0(0 \%)$ & $1(0.3 \%)$ \\
\hline Placental insufficiency & $1(0.4 \%)$ & $0(0 \%)$ & \\
\hline
\end{tabular}

Note: ${ }^{*}$ P between groups $=0.97$

Tabla 7: Classification of Body Mass Index.

\begin{tabular}{|c|c|c|}
\hline BMI classification & Total & Percentage \\
\hline Under weight & 2 & $0.5 \%$ \\
\hline Normal & 84 & $22 \%$ \\
\hline Overweight & 140 & $36.7 \%$ \\
\hline Obesity grade 1 & 97 & $25.4 \%$ \\
\hline Obesity grade 2 & 44 & $11.5 \%$ \\
\hline Obesity grade 3 & 14 & $3.6 \%$ \\
\hline Total & 381 & $100 \%$ \\
\hline
\end{tabular}

\begin{tabular}{|c|c|c|}
\hline Eclampsia & 97 & $25.4 \%$ \\
\hline Obesity grade 2 & 44 & $11.5 \%$ \\
\hline Total & 381 & $100 \%$ \\
\hline Total & 381 & $100 \%$ \\
\hline
\end{tabular}

Tabla 10: List of complications detected in the population.

Tabla 8: Prevalence of Hypertensive Disease of Pregnancy to Classifiers.

\begin{tabular}{|c|c|c|}
\hline Patients & Total & Percentage \\
\hline Without HDCP & 343 & $89.3 \%$ \\
\hline With HDCP & 41 & $10.6 \%$ \\
\hline Total & 384 & $100 \%$ \\
\hline
\end{tabular}

Tabla 9: Types of HDCP in the population.

\begin{tabular}{|c|c|c|}
\hline HDCP type & Total & Percentage \\
\hline Gestational hypertension & 2 & $0.5 \%$ \\
\hline Mild preeclampsia & 84 & $22 \%$ \\
\hline Severe preeclampsia & 140 & $36.7 \%$ \\
\hline
\end{tabular}

\begin{tabular}{|c|c|c|}
\hline Complication & Frequency & Percentage \\
\hline Infected surgical wound & 3 & $0.78 \%$ \\
\hline $\begin{array}{c}\text { Infected surgical wound + } \\
\text { endometritis }\end{array}$ & 1 & $0.26 \%$ \\
\hline Dehiscent surgical wound & 1 & $0.26 \%$ \\
\hline Fecal impaction & 1 & $0.26 \%$ \\
\hline Puncture warned & 1 & $0.26 \%$ \\
\hline $\begin{array}{c}\text { Retention of placental } \\
\text { remains }\end{array}$ & 1 & $0.26 \%$ \\
\hline Total & 8 & $2.08 \%$ \\
\hline
\end{tabular}

Few complications were found in the study population (Table 10). Of the 384 recruited patients, 4 presented an infected surgical wound; however, since the diagnosis of endometriosis was added to one of them, it was decided to place it in a different section. (Table 11) reflects the perinatal results of the products, describing the total $\mathrm{N}$ of patients obtained according to each diagnosis, weight, height, Apgar, and gestational age by capurro of each of them. 
Information on newborns in group 1: $\mathrm{N}=281$ In relation to the group of newborns of patients belonging to group 1, a total of 137 women was obtained, equivalent to $49 \%$ and 144 men, that is, $51 \%$ of the births, the average weight at birth was 3310.58g (412.75), as well as a size of $50 \mathrm{~cm}$ (49-52), with an Apgar of 8 (8 - 8) at the first minute and $9(9-9)$ at 5 minutes of extrauterine life, with an average gestational age of 39.2 (38.3 - 40). Information on newborns in group 2: $\mathrm{N}=101$ This group includes 101 births, of which 60 correspond to men, that is, $59 \%$ and 41 to women, corresponding to the remaining $41 \%$. As general information, the average weight of the RN 3376.43grs (409.26), height 50cm (49 - 52), Apgar at the first minute of 8 (8 - 8) was collected with a revaluation of 9 (9-9) at 5 minutes; with an average gestational age per delivery of 39.2 (38.3 - 40.4).

Tabla 11: Perinatal Outcomes in Newborns.

\begin{tabular}{|c|c|c|c|c|c|c|}
\hline Diagnosis & $\mathbf{N}$ & Weight (gr) & Size $(\mathrm{cm})$ & $\begin{array}{l}\text { Apgar to the 1st } \\
\text { minute }\end{array}$ & $\begin{array}{l}\text { Apgar to the } 5 \text { th } \\
\text { minute }\end{array}$ & Capurro \\
\hline CPDxPN & 130 & $3381(2350-4900)$ & $50.9(42-56)$ & $7.81(7-9)$ & $8.92(8-9)$ & $39.1(36.3-42)$ \\
\hline $\begin{array}{l}\text { Contraction } \\
\text { dystocia }\end{array}$ & 56 & $3369(2720-4140)$ & $50.3(46-54)$ & $7.81(7-9)$ & $8.92(8-9)$ & $39.2(37-41.3)$ \\
\hline Failed induction & 50 & $3369(2800-4000)$ & $50.3(40-54$ & $7.88(5-9)$ & $8.86(8-9)$ & $39.5(36-41.6)$ \\
\hline Acute fetal distress & 34 & $3200(2600-3900)$ & $49.9(40-54$ & $7.41(4-9)$ & $8.73(7-9)$ & $39(36-41)$ \\
\hline Condylomato-sis & 32 & $3134(2520-3800)$ & $49.5(45-53)$ & $7.87(5-9$ & $9(9-9)$ & $39.2(36.5-41.4)$ \\
\hline $\begin{array}{l}\text { Product in pelvic } \\
\text { presentation }\end{array}$ & 29 & $3057(2380-3660)$ & $48.5(42-52$ & $7.64(6-8)$ & $8.89(8-9)$ & $39.2(36.5-41.4)$ \\
\hline $\begin{array}{l}\text { Macrosomic } \\
\text { product }\end{array}$ & 28 & $3900(3040-4680$ & $52.4(49-56$ & $8.1(7-9)$ & $9(9-9)$ & $40(37.5-41.5)$ \\
\hline CTGR class II & 12 & $3003(2360-3540)$ & $50.5(48-56)$ & $7.74(7-9)$ & $8.83(7-10)$ & $39.1(37.4-40.5)$ \\
\hline OOP & 3 & $3146(3060-3200)$ & $50.3(49-52)$ & $7(6-8)$ & $9(9-9)$ & $39.1(38.4-39.2)$ \\
\hline Eclampsia & 2 & $2790(2700-2880)$ & $48.5(48-49)$ & $6(4-8)$ & $8.5(8-9$ & $38(37.6-38.4)$ \\
\hline $\begin{array}{c}\text { Severe } \\
\text { preeclampsia }\end{array}$ & 2 & $3430(3120-3740)$ & $50(50-50)$ & $8(8-8)$ & $9(9-9)$ & $38.2(38.1-38.3)$ \\
\hline $\begin{array}{l}\text { Uncertain fetal } \\
\text { status }\end{array}$ & 2 & $2860(2560-3160$ & $48(47-49)$ & $8(8-8)$ & $9(9-9)$ & $38(37-38.5)$ \\
\hline $\begin{array}{l}\text { Transverse } \\
\text { situation }\end{array}$ & 1 & 3180 & 49 & 8 & 9 & 37.1 \\
\hline OTT (+) & 1 & 2560 & 47 & 8 & 9 & 38.1 \\
\hline $\begin{array}{l}\text { Umbilical cord } \\
\text { prolapse }\end{array}$ & 1 & 2880 & 49 & 8 & 9 & 38.1 \\
\hline $\begin{array}{l}\text { Placental } \\
\text { insufficiency }\end{array}$ & 1 & 3220 & 50 & 8 & 9 & 40.6 \\
\hline
\end{tabular}

Information on newborns in group 3: $\mathrm{N}=2$ This group was the one with the lowest number of patients collected, with only 2 patients, of whom said births were women, with an average weight of $3640 \mathrm{~g}$ (650.53), with a size of $52 \mathrm{~cm} 52$ (52 - 52), Apgar at the first minute of $7.5(7-7.5)$, and at 5 minutes of $9(9-9)$, with an average gestational age of 39.3 (39 - 39.3). In this study, there were no maternal deaths or NICU admissions of newborns.

\section{Discussion}

Due to the increased caesarean section and long-term complications, an investigation was carried out on the main indications. Without finding a significant difference between the age groups of under 20 years, 21 - 35 years and over 36 years. In general, we found that the main indications for caesarean section were: Cephalopelvic disproportion due to pelvic tightness, contraction dystocia and failed induction. These results may lead us to suppose that, as the majority of our patients are in the group of patients under 20 years of age, a lack of development could condition CPD.
Related to the study by Samira Ebrahimzadeh Zagami, MSc et al we can make a relation between CPD and contraction dystocia due to an alteration in the contraction capacity of the myometrium. It also suggests making the diagnosis of cephalopelvic disproportion as quickly as possible to prevent prolonged labor or labor with dystocia. It also found that patients with contraction dystocia have a lower frequency of contractions compared to patients who ended up in vaginal delivery [10]. Continuing in the analysis of the diagnoses as a cause of caesarean section, is the failed induction; In the article published by Corina Schoen MD et al, the lack of an exact decision on failed induction is explained, explaining multiple definitions such as failure in vaginal birth care, failure to reach the active phase of labor, failure in the development of labor despite the use of cervical ripening agents.

At the same time, explains the Friedman Curve (1950), as a tool in evaluating the evolution and / or progression of labor, but which is currently no longer effective, explaining how in recent studies, 
observes a progression in both nulliparous and multiparous patients up to $6 \mathrm{~cm}$ dilation in a similar way; and that is why, this curve cannot be applied in the obstetric population. And it is suggested to mark the $6 \mathrm{~cm}$ of cervical dilation as the beginning of active phase labor, making a relation with our population has as null risk factor to establish the diagnosis of failed induction the nulliparity of the patients. Which is related to the aforementioned study [11]. Likewise, it describes potential situations that may predispose or favor a failure in induction of labor, such as obesity, lack of cervical maturity, nulliparity. It is exposed how there is a greater risk of ending up with a cesarean section, in a patient who begins an induction of labor in relation to patients who develop labor spontaneously [11]. Currently, the obstetrician has tools to assess fetal status during labor, such as the cardiotocographic record (CTGR),in this study found as an indication of abdominal interruption, CTGR class 2 as well as uncertain fetal status and acute fetal distress; An analysis of the literature found an article published by Maged $M$ et al explaining that there is no significant difference between intermittent auscultation of the FHR and continuous monitoring of the FHR with fetal outcomes (perinatal death and NICU admissions) [12].

At the same time, they explain the possible causes of altered results (false-positive, false-negative, etc.), due to the amount of stress and work that doctors go through during their workday. Carrying out an analysis with that published by Lynn L. Simpson, MD; which describes how the poor presentation of the product can be one of the indications, mentioning that among the most frequent are the pelvic presentation and the variety of persistent posterior occipito position. In our study, within the total population analyzed, we found indications for caesarean section, pelvic presentation, the variety of OPP position and a product in a transverse situation were the most common, coinciding with the findings of Simpson, who also explains the possibility of external version, through which the placement of the NB is favorable for vaginal delivery care [13].

Another of the maternal-fetal indications is fetal macrosomia, analyzing the weights of newborns modifying by cesarean section with the suspicion of macrosomia, a range ranging from $3040 \mathrm{grs}$ to 4680 grs is obtained. This suggests that the assessment carried out in these patients is not effective in all of them; and as a suggestion, it is considered to suspect fetal macrosomia in the case of a PFE of $4500 \mathrm{grs}$ in patients with gestational diabetes mellitus and a weight greater than 5000grs in cases of patients without GDM Likewise, adequate pelvimetry should be considered in patients [13]. In the information that was collected, it was found that the majority of complications were of infectious origin, when finding endometritis and the infected wound, which is comparable to what was stated by Manrique Fuentes, who makes a detailed analysis of how this type of complications can be avoided by using antibiotic prophylaxis, reducing the time in labor, evaluating the PRM time before surgery, the type of surgical technique used, etc [14]. Within the main limitations of this study, it is found that only the included population are primiparous patients, as well as the majority of them are adolescents.

\section{Conclusion}

There is no significant difference between the main indications for caesarean section in primigraphic patients between the group of adolescents, young adults and adults over 35 years of age. There were no maternal deaths or admissions to the NICU room during the study. The main complications presented by the patients were of infectious origin. Overweight is present in the majority of the population. The three main indications for cesarean section were cephalopelvic disproportion due to pelvic tightness, contraction dystocia, and failed induction.

\section{References}

1. Puentes Rosas E, Gómez Dantés O, Garrido Latorre F (2004) Las Cesáreas en México: tendencias, niveles y factores asociados. Salud Pública Mex 46: $16-22$

2. Gutiérrez JP, Rivera Dommarco J, Shamah Levy T, Villalpando Hernández S, Franco A, et al. (2012) Encuesta Nacional de Salud y Nutrición 2012. Resultados Nacionales. Cuernavaca México. Instituto Nacional de Salud Pública (MX): 74-91.

3. Gazala Y, Aruna K, Bharth P (2014) Teenage Pregnancy - Its Impact on Maternal and Fetal Outcome. Int J Sci Study 1:9-13.

4. Umesawa M, Kobashi G (2016) Epidmiology of Hipertensive Disorders in Pregnancy: Prevalence, Risk Factors, Predictors and Prognosis. Hypertens Res 40: 213-220.

5. Chamy V, Cardemil F, Betancour P, Ríos M, Leighton L (2009) Riesgo Obstétrico y Perinatal En Embarazadas Mayores De 35 Años. Rev Chil Obstet Ginecol 74: 331-338.

6. Garner A, Robertson A, Thornton C, Lee G, Makris A, et al. (2018) Adolescent Perinatal Outcomes in South West Sydney. Mayo Clin Proc Innov Qual Outcomes 2: 10-15.

7. Peña Ayudante W, Palacios J, Oscuvilca E, Peña A (2011) El Primer Embarazo en Mujeres Mayores de 35 Años de Edad. Revista Peruana de Ginecología y Obstetricia 53: 49-53.

8. Díaz A, Sanhueza P, Yaksic N (2002) Riesgos Obstétricos en el Embarazo Adolescente: Estudio Comparativo De Resultados Obstétricos y Perinatales Con Pacientes Embarazadas Adultas. Rev Chil Obstet Ginecol 67(6): 481-487.

9. Amaya J, Borrero C, Ucrós S (2005) Estudio Analítico del Resultado del Embarazo enAdolescentes y Mujeres de 20 a 29 Años en Bogotá. Rev Colomb Obstet Ginecol 56: 216-224.

10. Zagami S, Goldmakanji N, Ali Reza S, Ghomian N, Baghbani B (2015) The Shape of Uterine Contractions and Labor Progress in the Spontaneous Active Labor. Iran J Med Sci 40: 98103.

11. Schoen C, Navathe R (2015) Failed Induction of Labor. Seminars in Perinatology 39: 483-487.

12. Constantine M, Saade G (2012) The First Cesarean: Role of "Fetal Distress". Seminars in Perinatology 36: 379-383.

13. Simpson L (2012) When Is Primary Cesarean Appropriate: fetal Indications. Seminars in Perinatology 36: 328-335.

14. Manrique Fuentes MG (2009) Complicaciones de la Cesárea” del Servicio de Obstetricia y Ginecología, Hospital Universitario Virgen de las Nieves. Clase de Residentes. 
ISSN: 2574-1241

DOI: 10.26717/BJSTR.2020.27.004567

Mayela Diamantina Cruz Gutiérrez. Biomed J Sci \& Tech Res

(c) () This work is licensed under Creative

Submission Link: https://biomedres.us/submit-manuscript.php

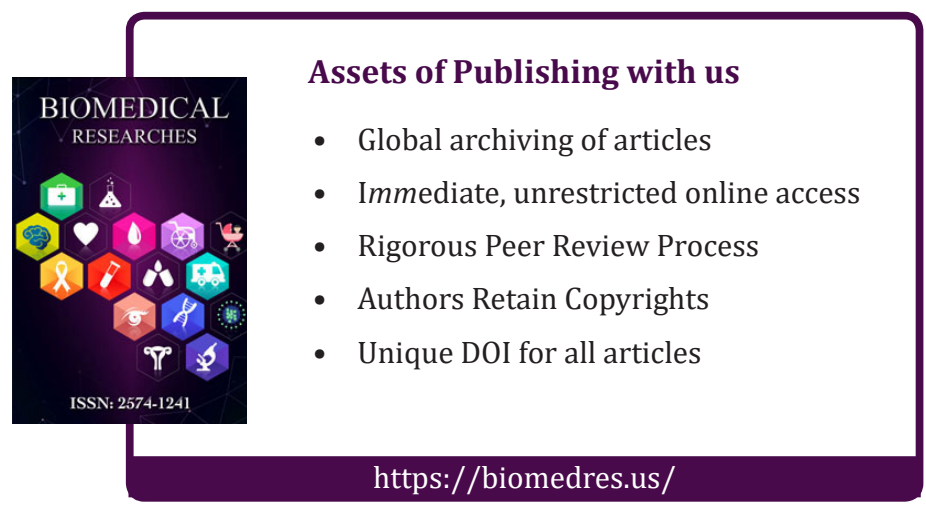

